\title{
Effort Oxygen Saturation and Effort Heart Rate to Detect Exacerbations of Chronic Obstructive Pulmonary Disease or Congestive Heart Failure
}

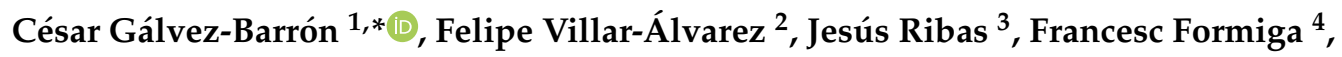 \\ David Chivite ${ }^{4}$, Ramón Boixeda ${ }^{5}$ (D) Cristian Iborra ${ }^{6}$ and Alejandro Rodríguez-Molinero ${ }^{1}$ \\ 1 Clinical Research Unit, Consorci Sanitari del Garraf, Sant Pere de Ribes, PC 08810 Barcelona, Spain; \\ arodriguez@csg.cat \\ 2 Department of Pulmonology, IIS Fundación Jiménez Díaz, CIBERES, UAM, PC 28040 Madrid, Spain; \\ FVillarA@quironsalud.es \\ 3 Servei de Pneumologia, Hospital Universitari de Bellvitge, IDIBELL, L'Hospitalet de Llobregat, \\ PC 08907 Barcelona, Spain; jribass@bellvitgehospital.cat \\ 4 Geriatric Unit. Internal Medicine Department, IDIBELL, Unversitat de Barcelona, \\ Hospital Universitari de Bellvitge, L’Hospitalet de Llobregat, PC 08907 Barcelona, Spain; \\ fformiga@bellvitgehospital.cat (F.F.); dchivite@bellvitgehospital.cat (D.C.) \\ 5 Internal Medicine Department, Hospital de Mataró-Consorci Sanitari del Maresme, PC 08304 Barcelona, \\ Spain; rboixedaviu@gmail.com \\ 6 Cardiology Department, IIS Fundación Jiménez Díaz, PC 28040 Madrid, Spain; \\ cristian.iborra@salud.madrid.org \\ * Correspondence: cgalvez@csg.cat; Tel.: +34-626-419-884
}

Received: 17 December 2018; Accepted: 26 December 2018; Published: 4 January 2019

\begin{abstract}
Background: current algorithms for the detection of heart failure (HF) and chronic obstructive pulmonary disease (COPD) exacerbations have poor performance. Methods: this study was designed as a prospective longitudinal trial. Physiological parameters were evaluated at rest and effort (walking) in patients who were in the exacerbation or stable phases of HF or COPD. Parameters with relevant discriminatory power (sensitivity (Sn) or specificity $(\mathrm{Sp}) \geq 80 \%$, and Youden index $\geq 0.2$ ) were integrated into diagnostic algorithms. Results: the study included 127 patients (COPD: 56, HF: 54 , both: 17). The best algorithm for COPD included: oxygen saturation $\left(\mathrm{SaO}_{2}\right)$ decrease $\geq 2 \%$ in minutes 1 to 3 of effort, end-of-effort heart rate (HR) increase $\geq 10$ beats $/ \mathrm{min}$ and walking distance decrease $\geq 35 \mathrm{~m}$ (presence of one criterion showed Sn: 0.90 (95\%, CI(confidence interval): 0.75-0.97), Sp: 0.89 (95\%, CI: 0.72-0.96), and area under the curve (AUC): 0.92 (95\%, CI: 0.85-0.995)); and for HF: $\mathrm{SaO}_{2}$ decrease $\geq 2 \%$ in the mean-of-effort, $\mathrm{HR}$ increase $\geq 10$ beats $/ \mathrm{min}$ in the mean-of-effort, and walking distance decrease $\geq 40 \mathrm{~m}$ (presence of one criterion showed Sn: 0.85 (95\%, CI: 0.69-0.93), Sp: 0.75 (95\%, CI: 0.57-0.87) and AUC 0.84 (95\%, CI: 0.74-0.94)). Conclusions: effort situations improve the validity of physiological parameters for detection of HF and COPD exacerbation episodes.
\end{abstract}

Keywords: chronic obstructive pulmonary disease; heart failure; diagnostic algorithms

\section{Introduction}

HF and COPD are among the chronic conditions with the highest adverse impact on the population [1-3]. HF and COPD exacerbations negatively influence survival, autonomy, and quality of life of individuals and are a common cause of hospitalization and visits to the emergency department [4-6].

Several detection models based on remote monitoring of clinical parameters such as dyspnea, $\mathrm{HR}$, respiratory rate (RR), $\mathrm{SaO}_{2}$, body weight, or body temperature have been developed for the rapid 
management of HF and COPD exacerbations. Frequently, the goal is to incorporate such models into a telemedicine platform.

The models developed to date can be defined as predictive (models predicting the medium-long term risk of exacerbations, when the patient is in a stable state) or diagnostic (models detecting an exacerbation episode which is already on course). Regarding diagnostic exacerbation models in HF [7-11] and COPD [12-21], they have shown variable and poor Sn ranging between $40-75 \%$. Ledwidge et al. [22] developed a HF diagnostic exacerbation model with higher Sn (82\%) though low Sp (68\%). Similarly, Shah et al. [23] have developed a COPD model with $80 \%$ Sn but, again, low Sp $(36 \%)$. The low $\mathrm{Sn}$ and $\mathrm{Sp}$ of these models restrict their use in routine clinical practice.

To improve the performance of such algorithms, the study of other clinical parameters has been proposed [12,24]. In this regard, no studies or algorithms developed up to now have considered the diagnostic performance of vital signs in effort situations (for example, while the patient is walking). Physical effort produces a physiological response (variations in the HR, $\mathrm{RR}$ or $\mathrm{SaO}_{2}$ ), which may be different depending on whether the patient is in a stable or an exacerbation phase of disease [25-27]. Additionally, physical effort may evidence alterations in certain parameters, which are not observed when the patient is evaluated at rest in the initial phases of an exacerbation episode. Therefore, the goal of the present study was to evaluate the differences in the physiological response to effort between patients in a stable/exacerbation phase of disease (HF and/or COPD) and, on the basis of such possible differences, to develop a model for detecting exacerbation episodes.

\section{Experimental Section}

\subsection{Design and Sample}

This study was designed as a prospective longitudinal trial. Subjects were recruited among patients who were hospitalized at the Internal Medicine, Cardiology or Pneumology Units with a main diagnosis of HF and/or COPD exacerbation (in this study, exacerbation was defined as a decompensation episode severe enough as to cause hospitalization). Included patients were older than 55 years and were able to walk for at least $30 \mathrm{~m}$ at the moment of evaluation. Patients with HF New York Heart Association (NYHA) functional class IV, patients with a pacemaker or intra-cardiac device, and patients on long-term oxygen therapy prior to recruitment were excluded.

Two third-level hospitals (university hospitals of reference at the national level with 300-1500 hospital beds and highly specialized units) plus two second-level hospitals (regional hospitals with 200-800 hospital beds, with 5 to 10 medical specialties including Internal Medicine, Cardiology and Pneumology) participated in the study, each one with a reference physician and a trained interviewer. Interviewers were in charge of visiting the corresponding center every day and contacting the reference physician in order to identify patients with a main diagnosis of HF or COPD exacerbation from the list of hospitalization units. Subsequently, the reference physician confirmed the diagnosis with the physicians in charge of those patients. Patients without such medical confirmation of the diagnosis were not included in the study.

We conducted a convenience sampling including all consecutive patients, who met the inclusion criteria, admitted to any of the participating hospitals during an 18-month period starting on November 2010. Assuming a case (patient in an exacerbation phase)/control (patient in a stable phase) proportion of 1, expected Sn and Sp of $80 \%$ and $90 \%$ respectively, and 10\% accuracy with a $95 \%$ confidence level, a total sample size of 124 subjects was calculated.

\subsection{Participants' Evaluation and Variables}

Every patient underwent three identical evaluation sessions in the following order (Figure 1): one session during hospital stay (V1), considered as an evaluation in an exacerbation phase, and two sessions at home (V2 and V3), considered as evaluations in a stable phase. V1 was carried out after the corresponding physician authorized the patient to walk (namely, after the most severe part of 
the process had passed). Thirty days after discharge, one of the research physicians contacted the participant via telephone to check whether he/she was in a stable phase. To this end, a questionnaire was administered, asking the patients whether, compared to the moment of hospital discharge, they had experienced increased cough, sputum, or dyspnea; increased the dose or re-started a corticoid therapy, initiated an antibiotic treatment, or visited the doctor due to the worsening of any clinical condition. If the answer to any of these questions was "yes", it was considered that the patient was not in a stable state. In such case, sessions (V2, V3) were postponed until the researcher considered, based on successive telephone calls, that the patient was in a stable state. Sessions V2 and V3 were scheduled with at least $24 \mathrm{~h}$ between them.

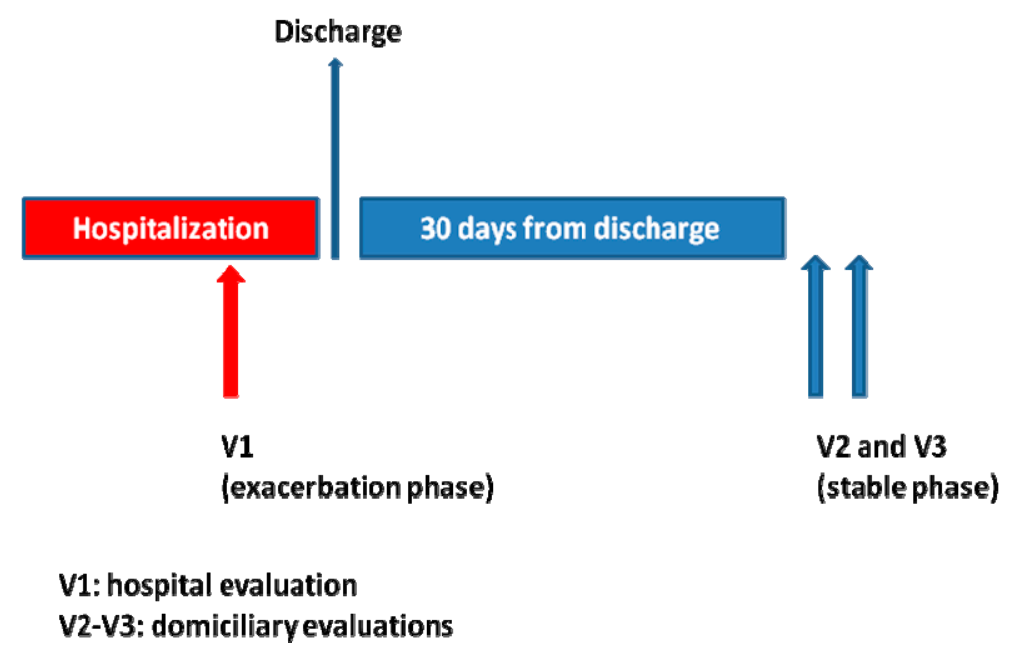

Figure 1. Timeline for evaluation sessions during the trial.

The interviewers evaluated the patients within $24-72 \mathrm{~h}$ following medical confirmation of the diagnosis of exacerbation or stable phase.

Interviewers were trained by the researchers, through theoretical and practical sessions, on the process of data collection and the way of conducting the evaluation sessions with the patients. On one day during the first three months of recruiting, every interviewer was accompanied by a researcher, to verify that the training had been adequate. Throughout the study, a telephone line was available to interviewers, to contact the reference physician and one of the researchers.

Every evaluation session consisted of 3 consecutive phases: rest (patient sitting for at least $20 \mathrm{~min}$ ), effort (walking on a flat non-tilted surface at the patient's usual pace for a maximum period of $6 \mathrm{~min}$ ) and recovery (4 min immediately following the termination of the effort phase, with the patient in the sitting position).

The main parameters that were evaluated were: $\mathrm{RR}, \mathrm{HR}, \mathrm{SaO}_{2}$, and walking distance $(\mathrm{m})$. The interviewer measured $\mathrm{SaO}_{2}$ and $\mathrm{HR}$ by placing a pulse oximeter with memory function (Model 3100, Nonin Medical, Inc., Plymouth, MN, USA) on the patient's left index finger at the end of the rest phase, just before the participant started walking. Both $\mathrm{SaO}_{2}$ and $\mathrm{HR}$ were measured continuously and per-minute means were subsequently calculated, using the device's software, throughout the effort and recovery phases. Interviewers measured the RR at the end of every phase, while using a distraction maneuver (i.e., they pretended to palpate the radial pulse). Interviewers measured the total walking distance with an odometer, while walking alongside the patients. No specific walking route was established; patients were allowed to walk at their convenience, along the hospital corridor or at home. However, walking was stopped in cases where the patient showed HR higher than 220 beats $/ \mathrm{min}$, $\mathrm{SaO}_{2}$ lower than $85 \%$, or dyspnea/ pain that prevented them from continuing to walk. In cases where the patient was using oxygen therapy at the moment of evaluation, it was discontinued at least $15 \mathrm{~min}$ before they started walking. 
Dyspnea was measured by using the NYHA scale [28], the modified Medical Research Council (mMRC) scale [29] and the Borg scale [30]. Blood pressure at rest, body weight, and body temperature were also recorded.

\subsection{Statistical Analysis}

Statistical analysis was carried out by splitting the sample into two groups, according to medical diagnosis (HF exacerbation/COPD exacerbation). Patients with both diagnoses were included in both groups.

Two types of discriminant analysis were conducted for every parameter. First, mean values from exacerbation (V1) and stable (V2) phases were compared (Student's T-test for paired samples). Second, differences (V1-V2) and (V3-V2) were calculated, where the first ones were considered cases (i.e., the differences between exacerbation phase V1 and stable phase V2) and the latter ones were considered controls (i.e., the differences between stable phase V3 and stable phase V2). On the basis of the calculated differences, all possible cutpoints were evaluated and Sn (case group) and Sp (control group) were calculated for every cutpoint. Given that the prevalence of cases in the study (stable/exacerbation proportion 1:1) was clearly higher than that usually reported in clinical practice, predictive values were not analyzed.

From the second analysis, parameters with relevant discriminatory power were selected and their combined diagnostic performance was evaluated using a serial and parallel testing strategy. In this study, the serial testing strategy consists of first determining the absence (negative result) or presence (positive result) of a certain parameter and, only in case of a positive result, the absence or presence of a second parameter is determined. The final result is only considered to be positive in those cases in which both parameters are positive (in this way, net $\mathrm{Sp}$ is strengthened, although net $\mathrm{Sn}$ is lowered). In the parallel testing strategy, the presence (positive result) or absence (negative result) of two or more parameters is simultaneously determined, and it is enough that one of them is positive to consider the final result as positive (net Sn is strengthened although net Sp is lowered) [31]. The requisites for a parameter to be considered relevant were: Youden index [32] equal to or higher than 0.2 plus one of the following: Sn of at least $80 \%$ (for the parallel testing strategy) or Sp of at least $80 \%$ (serial testing strategy).

In order to control for the effects of bradycardia-inducing drugs (beta-blockers, verapamil, diltiazem, digoxin, and amiodarone) and assuming that baseline HR is elevated during the course of a cardiac/respiratory exacerbation, participants who had been on treatment with a bradycardia-inducing drug during the stable phase (V2, V3) but not the exacerbation phase (V1) were excluded from the HR analysis. Pain and anxiety were evaluated using the Face Pain Scale $[33,34]$ and asking a direct question about the occurrence of anxiety. Outliers of physiological parameters $\mathrm{RR}(<8$ breaths $/ \mathrm{min}$ or $>40$ breaths $/ \mathrm{min}$ ) and rest HR ( $<30$ beats $/ \mathrm{min}$ or $>150$ beats $/ \mathrm{min})$, as well as lacking or lost results were excluded from the analysis.

Statistical analysis was conducted with the statistical software package SPSS Statistics 24 (IBM, Armonk, NY, USA).

This study was conducted in accordance with the amended Declaration of Helsinki and was approved by the Ethics Committee for Clinical Research of the Hospital of Mataró (Comité Ético de Investigación Clínica del Hospital de Mataró) (approval number: 1851806) and those of the other participating centers. Informed consent was obtained from all participants.

\section{Results}

\subsection{Demographics}

A total of 127 participants were recruited (56 with COPD exacerbation, 54 with HF exacerbation and 17 with exacerbation of both conditions). Figure 2 shows the number of participants who completed the follow-up and the reasons behind cases lost to follow-up. Table 1 shows the baseline results per HF or COPD condition. 


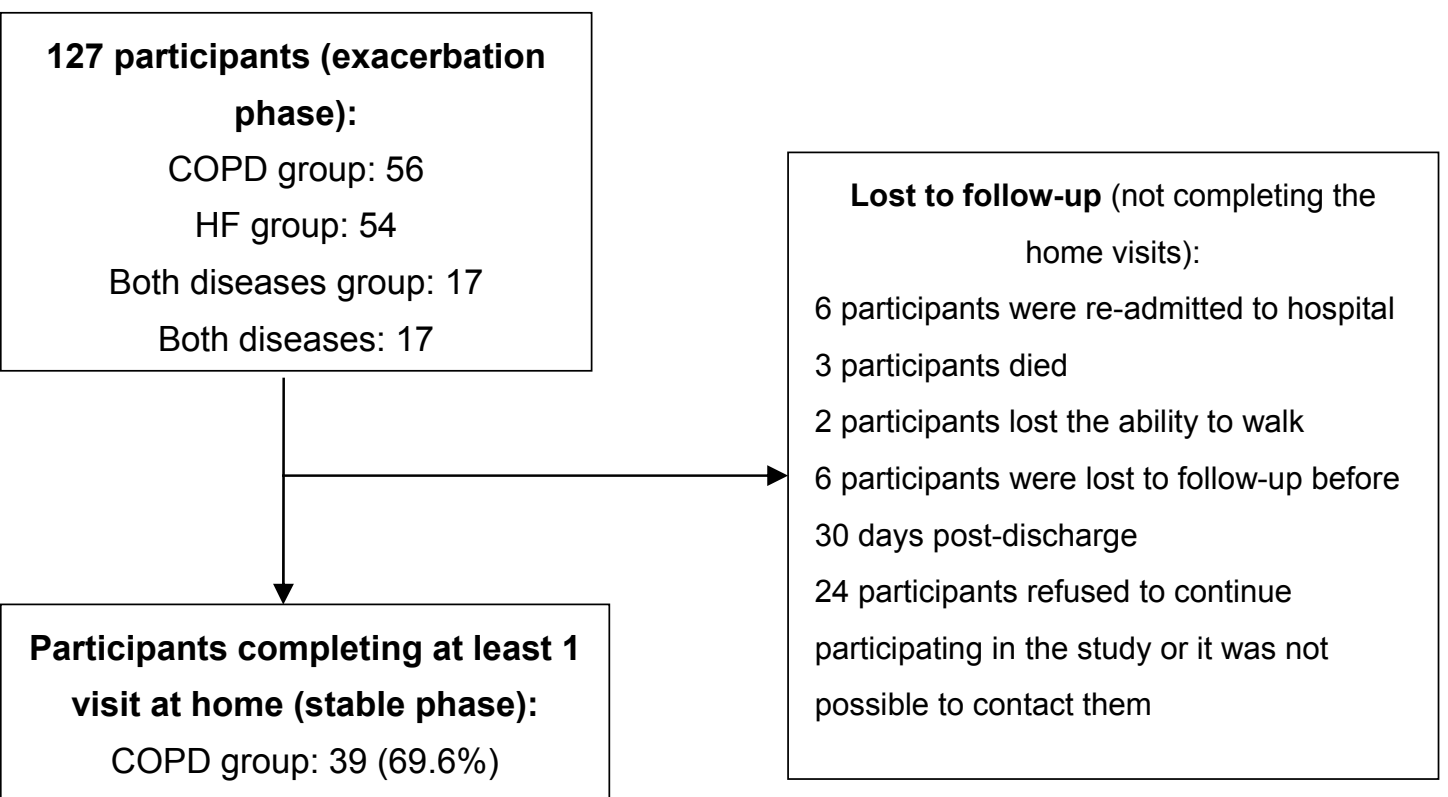

HF group: $32(59.3 \%)$

Both diseases group: $15(88.2 \%)$

Figure 2. Participant recruiting and follow-up.

Table 1. Distribution of baseline characteristics according to disease.

\begin{tabular}{|c|c|c|c|c|}
\hline & HF $(n=54)$ & COPD $(n=56)$ & Both $(n=17)$ & $p$ \\
\hline Age (SD) & $78.4(8.3)$ & $73.4(8.4)$ & $75.8(9.6)$ & 0.010 \\
\hline Male (\%) & $24(44.4)$ & $43(76.8)$ & $16(94.1)$ & $<0.01$ \\
\hline Diabetes mellitus $2(\%)$ & $27(50.0)$ & $11(19.6)$ & $6(35.3)$ & 0.002 \\
\hline Dyslipidemia (\%) & $16(29.6)$ & $21(37.5)$ & $5(29.4)$ & 0.707 \\
\hline Active smoking (\%) & $2(3.7)$ & $13(23.2)$ & $1(5.9)$ & 0.008 \\
\hline $\begin{array}{l}\text { Treatment with bradycardia-inducing } \\
\text { drug (previous to current } \\
\text { exacerbation) }(\%)\end{array}$ & $37(68.5)$ & $7(12.5)$ & $12(70.6)$ & $<0.01$ \\
\hline $\begin{array}{l}\text { Previous hospitalization due to } \\
\text { cardiac/respiratory disease (SD) }\end{array}$ & $0.9(1.2)$ & $1.9(1.9)$ & $1.7(1.4)$ & 0.007 \\
\hline Length of stay in days (SD) & $9(8.1)$ & $11.3(11.4)$ & $7.9(7.0)$ & 0.445 \\
\hline $\begin{array}{l}\text { Baseline evaluation time (days } \\
\text { previous to discharge) (SD) }\end{array}$ & $2.3(3.8)$ & $3.8(4.4)$ & $2.9(2.7)$ & 0.299 \\
\hline \multicolumn{5}{|l|}{ Dyspnea (NYHA) (\%) } \\
\hline I & $16(29.6)$ & $16(28.6)$ & $5(29.4)$ & \multirow{3}{*}{0.924} \\
\hline II & $22(40.7)$ & $20(35.7)$ & $8(47.1)$ & \\
\hline III & $16(29.6)$ & $20(35.7)$ & $4(23.5)$ & \\
\hline \multicolumn{5}{|l|}{ Dyspnea (mMRC) (\%) } \\
\hline 0 & $12(22.2)$ & $14(25)$ & $4(23.5)$ & \multirow{4}{*}{0.391} \\
\hline 1 & 6 (11.1) & $9(16.1)$ & $2(11.8)$ & \\
\hline 2 & $13(24.1)$ & $16(28.6)$ & $4(23.5)$ & \\
\hline 3 & $23(42.6)$ & $17(30.4)$ & $7(41.2)$ & \\
\hline Body mass index (SD) & $26.7(4.6)$ & $25.2(4.4)$ & $26.8(8.2)$ & 0.235 \\
\hline Osteoarthritis (\%) & $35(64.8)$ & $25(44.6)$ & $7(41.2)$ & 0.055 \\
\hline
\end{tabular}

Dyspnea results correspond to the degree of limitation at the moment of baseline evaluation (exacerbation phase at hospital). HF: heart failure; COPD: chronic obstructive pulmonary disease; NYHA: New York Heart Association; mMRC: modified Medical Research Council; SD: standard deviation; \%: percentage; $n$ : sample size. 


\subsection{Mean and Diagnostic Performance of Individual Parameters}

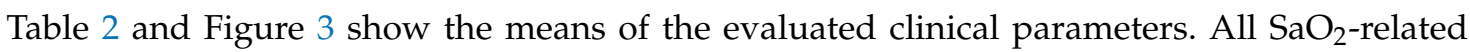
parameters varied significantly between the exacerbation vs. stable phase for both diseases, although the largest differences were for COPD.

Table 3 shows the clinical parameters with relevant discriminatory power. There were at least one $\mathrm{SaO}_{2}$, one $\mathrm{HR}$, and one walking distance parameter considered as such, for both conditions. None of the parameters showed Sn and Sp higher than $80 \%$ simultaneously. Dyspnea, blood pressure, RR, and body weight did not show relevant discriminatory power. Changes between rest (patient seated) vs. effort (initiation of walking) and between effort (termination of walking) vs. recovery (patient resting seated) did not show relevant discriminatory power either, for differentiating the exacerbation from the stable phase.

It was not necessary to exclude any value due to outlier criteria; 14 patients were excluded from the HR analysis because they were on a treatment with a bradycardia-inducing drug in the stable phase but not in the exacerbation phase $(8,3$ and 3 patients from the HF, COPD and both conditions groups, respectively). The frequency of pain and anxiety did not change significantly between the stable/exacerbation phases.

Table 2. Physiological parameters according to disease and exacerbation/stable phase.

\begin{tabular}{|c|c|c|c|c|c|c|c|c|}
\hline \multirow{2}{*}{$\begin{array}{l}\text { Clinical } \\
\text { Parameter }\end{array}$} & \multicolumn{4}{|c|}{$\mathrm{HF}$} & \multicolumn{4}{|c|}{ COPD } \\
\hline & $\begin{array}{l}\text { Exacerb. } \\
\text { Phase (SD) }\end{array}$ & $\begin{array}{c}\text { Stable } \\
\text { Phase (SD) }\end{array}$ & $\begin{array}{l}\text { Mean Difference } \\
(95 \% \mathrm{CI})\end{array}$ & $p$ & $\begin{array}{l}\text { Exacerb. } \\
\text { phase (SD) }\end{array}$ & $\begin{array}{c}\text { Stable } \\
\text { Phase (SD) }\end{array}$ & $\begin{array}{l}\text { Mean Difference } \\
(95 \% \mathrm{CI})\end{array}$ & $p$ \\
\hline \multicolumn{9}{|l|}{$\begin{array}{l}\text { Oxygen saturation } \\
\qquad(\%)\end{array}$} \\
\hline Rest & $92.7(3.4)$ & $94.1(3.2)$ & $-1.36(-2.42 ;-0.3)$ & 0.01 & $90.6(3.2)$ & $93.6(2.6)$ & $-2.96(-3.77 ;-2.16)$ & $<0.001$ \\
\hline $\begin{array}{l}\text { Minute } 1 \text { to } 3 \text { of } \\
\text { effort (mean) }\end{array}$ & $92.2(3.6)$ & $94(3.1)$ & $-1.79(-2.65 ;-0.93)$ & $<0.001$ & $89.4(3.9)$ & $92.2(3.2)$ & $-2.84(-3.91 ;-1.77)$ & $<0.001$ \\
\hline End-of-effort & $91(5.6)$ & $92.6(4.1)$ & $-1.64(-2.82 ;-0.46)$ & 0.01 & $88.1(5.1)$ & $91.1(4.3)$ & $-3.04(-4.16 ;-1.91)$ & $<0.001$ \\
\hline $\begin{array}{l}\text { Mean-of-effort } \\
\text { period }\end{array}$ & $91.2(3.7)$ & $92.8(3.4)$ & $-1.63(-2.45 ;-0.81)$ & $<0.001$ & $88.7(3.7)$ & $91.3(3.5)$ & $-2.57(-3.42 ;-1.72)$ & $<0.001$ \\
\hline End-of-recovery & $93.9(2.9)$ & $95.1(2.5)$ & $-1.23(-1.96 ;-0.51)$ & $<0.001$ & $92(3.1)$ & $94.7(2.5)$ & $-2.72(-3.56 ;-1.87)$ & $<0.001$ \\
\hline $\begin{array}{c}\text { Mean of recovery } \\
\text { period }\end{array}$ & $92.3(3.4)$ & $93.7(3.2)$ & $-1.42(-2.28 ;-0.57)$ & $<0.001$ & $90.5(3.5)$ & $93(3.1)$ & $-2.48(-3.39 ;-1.57)$ & $<0.001$ \\
\hline \multicolumn{9}{|l|}{$\begin{array}{c}\text { Heart rate } \\
\text { (beats } / \mathrm{min})^{(1)}\end{array}$} \\
\hline Rest & $80.1(12.2)$ & $72.9(11.4)$ & $7.22(2.11 ; 12.33)$ & 0.01 & $87.3(15.4)$ & $79.9(14.5)$ & $7.4(3.05 ; 11.74)$ & $<0.001$ \\
\hline $\begin{array}{l}\text { Minute } 1 \text { to } 3 \text { of } \\
\text { effort (mean) }\end{array}$ & $84.1(9.9)$ & 13.9) & $2.95(-2.6 ; 8.49)$ & 0.29 & $89.8(14.6)$ & $87.5(16.8)$ & $2.21(-3.45 ; 7.88)$ & 0.43 \\
\hline End-of-effort & $90.2(12.3)$ & $88.9(16.1)$ & $1.28(-4.91 ; 7.47)$ & 0.68 & $99(16.2)$ & $93.6(16.8)$ & $5.42(0.84 ; 9.99)$ & 0.02 \\
\hline $\begin{array}{l}\text { Mean-of-effort } \\
\text { period }\end{array}$ & $87.2(9.5)$ & $83.2(13.1)$ & $3.97(-0.74 ; 8.68)$ & 0.1 & $93.3(12.4)$ & $89.8(14.7)$ & $3.47(-1.18 ; 8.11)$ & 0.14 \\
\hline End-of-recovery & $78.7(14.6)$ & $75.6(13.3)$ & $3.06(-2.13 ; 8.24)$ & 0.24 & $89.3(14.9)$ & $81.9(13.2)$ & $7.4(3.05 ; 11.76)$ & $<0.001$ \\
\hline $\begin{array}{c}\text { Mean of recovery } \\
\text { period }\end{array}$ & $83.5(11.6)$ & $80(13.9)$ & $3.5(-2.01 ; 9.01)$ & 0.21 & $89.4(13.6)$ & $86.2(14.4)$ & $3.19(-1.42 ; 7.8)$ & 0.17 \\
\hline \multicolumn{9}{|l|}{$\begin{array}{l}\text { Respiratory rate } \\
\text { (breaths } / \mathrm{min} \text { ) }\end{array}$} \\
\hline Rest & $21.4(5.1)$ & $20.8(4.5)$ & $0.57(-0.74 ; 1.88)$ & 0.38 & $21.2(5.1)$ & $21.2(4.6)$ & $0.02(-0.92 ; 0.95)$ & 0.97 \\
\hline End-of-effort & $24.5(5.3)$ & $23.6(5.3)$ & $0.85(-0.43 ; 2.13)$ & 0.19 & $24.7(5.6)$ & $23.9(5)$ & $0.85(-0.07 ; 1.77)$ & 0.07 \\
\hline End-of-recovery & $22(5.5)$ & $21.3(4.7)$ & $0.65(-0.78 ; 2.08)$ & 0.36 & $22.5(4.6)$ & $21.3(4.1)$ & $1.19(0.21 ; 2.17)$ & 0.02 \\
\hline $\begin{array}{c}\text { Distance }(\mathrm{m}) \\
\text { Walking distance }\end{array}$ & $126.7(89.8)$ & $133.1(82.5)$ & $-6.36(-31.3 ; 18.57)$ & 0.61 & $134.1(93.8)$ & $157.9(100.2)$ & $-23.78(-49.99 ; 2.42)$ & 0.07 \\
\hline \multicolumn{9}{|l|}{ Dyspnea } \\
\hline NYHA scale & $2.1(0.9)$ & $1.9(0.7)$ & $0.17(-0.05 ; 0.39)$ & 0.13 & $2.1(0.9)$ & $1.8(0.7)$ & $0.28(0.01 ; 0.55)$ & 0.04 \\
\hline mMRC scale & $2(1.2)$ & $1.7(1.1)$ & $0.28(-0.02 ; 0.57)$ & 0.06 & $1.7(1.4)$ & $1.5(1.3)$ & $0.24(-0.15 ; 0.63)$ & 0.22 \\
\hline Borg scale (rest) & $1.7(1.3)$ & $1.7(1.5)$ & $-0.09(-0.61 ; 0.44)$ & 0.75 & $1.6(1.3)$ & $1.6(1.3)$ & $0.04(-0.45 ; 0.52)$ & 0.88 \\
\hline Borg scale (effort) & $2.7(1.9)$ & $3.1(2.4)$ & $-0.43(-1.2 ; 0.35)$ & 0.27 & $3.3(2.5)$ & $2.9(2.4)$ & $0.41(-0.45 ; 1.27)$ & 0.35 \\
\hline \multicolumn{9}{|l|}{ Blood pressure } \\
\hline Systolic pressure & $120.1(19.6)$ & $125.1(23.6)$ & $-5.04(-10.75 ; 0.66)$ & 0.08 & $125.4(18.3)$ & $126.7(20.3)$ & $-1.28(-6.85 ; 4.29)$ & 0.65 \\
\hline Diastolic pressure & $70.4(13.3)$ & $70(13.4)$ & $0.38(-3.77 ; 4.53)$ & 0.85 & $73.8(10.8)$ & $73.7(12.1)$ & $0.07(-3.33 ; 3.48)$ & 0.97 \\
\hline
\end{tabular}

For cases in which the difference between means reached significance, the differences between both stable-phase visits (V2 vs. V3) were calculated in order to determine whether the observed differences corresponded to biological variability. No case differences due to biological variability were found except for the end-of-recovery respiratory rate, both in COPD and HF patients. (1): Heart rate values from patients, who were indicated treatment with a bradycardia-inducing drug upon discharge but not during hospital stay, were excluded (14 patients). HF: heart failure, COPD: chronic obstructive pulmonary disease, NYHA: New York Heart Association, mMRC: modified Medical Research Council, SD: standard deviation; CI: confidence interval. 


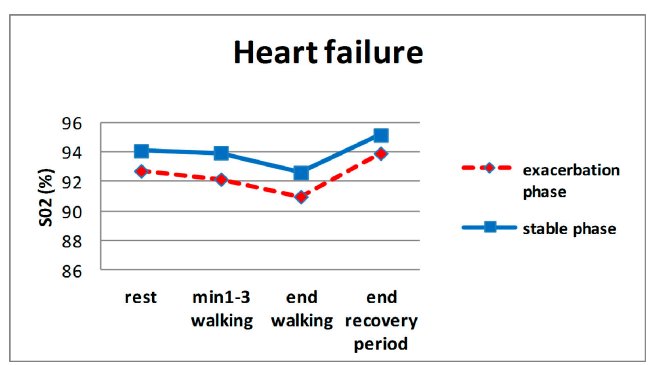

(a)

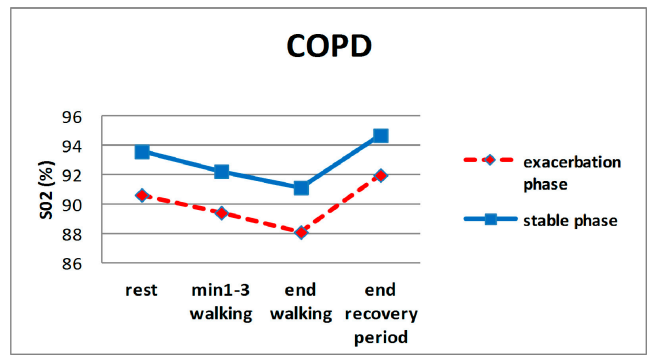

(c)

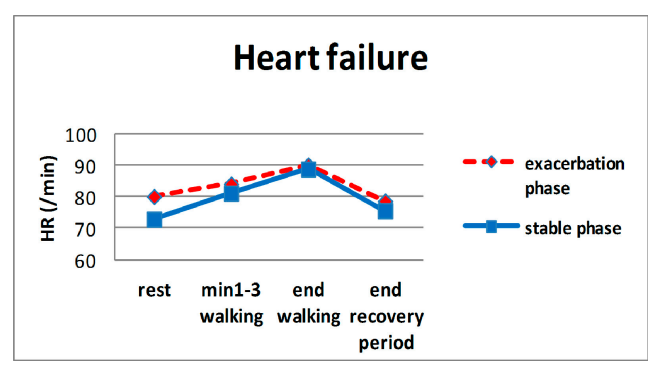

(b)

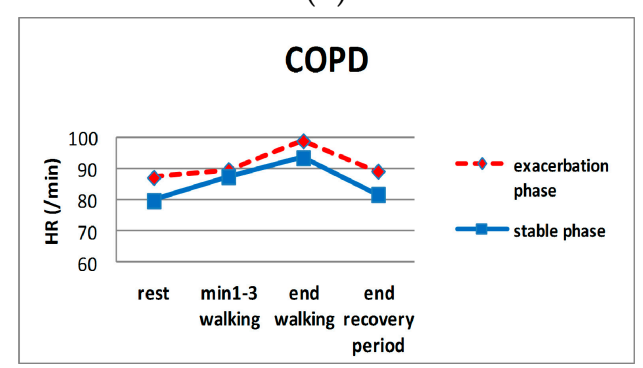

(d)

Figure 3. $\mathrm{HR}$ and $\mathrm{SaO}_{2}$ during evaluation sessions. (a,b): $\mathrm{SaO}_{2}$ and $\mathrm{HR}$ of HF patients, respectively; (c,d): $\mathrm{SaO}_{2}$ and $\mathrm{HR}$ of COPD patients, respectively.

Table 3. Parameters with relevant discriminatory power ${ }^{(1)}$ for detection of clinical exacerbation.

\begin{tabular}{|c|c|c|c|c|c|c|c|c|c|}
\hline \multirow{2}{*}{ Clinical Parameter } & \multirow{2}{*}{ Cutpoint ${ }^{(2)}$} & \multicolumn{4}{|c|}{ HF } & \multicolumn{4}{|c|}{ COPD } \\
\hline & & $n$ & Sn $(95 \%$ CI) & $n$ & Sp (95\% CI) & $n$ & Sn $(95 \%$ CI) & $n$ & Sp $(95 \%$ CI $)$ \\
\hline \multicolumn{10}{|c|}{ Oxygen saturation (\%) } \\
\hline \multirow{3}{*}{ Rest } & $\geq 1$ & & & & & 54 & $0.85(0.73-0.92)$ & 46 & $0.72(0.57-0.83)$ \\
\hline & 2 & 47 & $0.53(0.39-0.67)$ & 43 & $0.86(0.73-0.93)$ & & & & \\
\hline & 3 & 47 & $0.34(0.22-0.48)$ & 43 & $0.95(0.85-0.99)$ & & & & \\
\hline Minute 1 to 3 of effort (mean) & 2 & 35 & $0.4(0.26-0.56)$ & 33 & $0.91(0.76-0.97)$ & 35 & $0.57(0.41-0.72)$ & 29 & $0.93(0.78-0.98)$ \\
\hline End-of-effort & 3 & & & & & 54 & $0.5(0.37-0.63)$ & 46 & $0.87(0.74-0.94)$ \\
\hline Mean-of-effort period & 2 & 46 & $0.46(0.32-0.6)$ & 40 & $0.88(0.74-0.95)$ & & & & \\
\hline \multirow{2}{*}{ End-of-recovery } & 2 & 47 & $0.51(0.37-0.65)$ & 43 & $0.88(0.76-0.95)$ & & & & \\
\hline & 3 & 47 & $0.28(0.17-0.42)$ & 43 & $0.95(0.85-0.99)$ & 53 & $0.53(0.4-0.66)$ & 46 & $0.89(0.77-0.95)$ \\
\hline \multirow{2}{*}{ Mean of recovery period } & 2 & 45 & $0.47(0.33-0.61)$ & 40 & $0.88(0.74-0.95)$ & & & & \\
\hline & 3 & 45 & $0.31(0.2-0.46)$ & 40 & $0.93(0.8-0.97)$ & 48 & $0.44(0.31-0.58)$ & 38 & $0.89(0.76-0.96)$ \\
\hline \multicolumn{10}{|c|}{ Heart rate (beats/min) } \\
\hline \multirow{2}{*}{ Rest } & $\geq 10$ & 36 & $0.42(0.27-0.58)$ & 32 & $0.84(0.68-0.93)$ & & & & \\
\hline & 15 & 36 & $0.36(0.22-0.52)$ & 32 & $0.91(0.76-0.97)$ & 48 & $0.31(0.2-0.45)$ & 41 & $0.95(0.84-0.99)$ \\
\hline Minute 1 to 3 of effort (mean) & 10 & 31 & $0.42(0.26-0.59)$ & 26 & $0.92(0.76-0.98)$ & 33 & $0.3(0.17-0.47)$ & 27 & $0.93(0.77-0.98)$ \\
\hline End-of-effort & 10 & & & & & 48 & $0.4(0.27-0.54)$ & 41 & $0.93(0.81-0.97)$ \\
\hline Mean-of-effort period & 10 & 35 & $0.4(0.26-0.56)$ & 29 & $0.97(0.83-0.99)$ & & & & \\
\hline \multirow{2}{*}{ Mean of recovery period } & 10 & 34 & $0.35(0.21-0.52)$ & 29 & $0.93(0.78-0.98)$ & & & & \\
\hline & 15 & 34 & $0.26(0.15-0.43)$ & 29 & $1(0.88-1)$ & & & & \\
\hline \multicolumn{10}{|c|}{ Walking distance $(\mathrm{m})$} \\
\hline Walking distance difference & $\geq 35$ & 44 & $0.34(0.22-0.49)$ & 42 & $0.95(0.84-0.99)$ & 51 & $0.43(0.31-0.57)$ & 46 & $0.93(0.82-0.98)$ \\
\hline & 40 & 44 & $0.34(0.22-0.49)$ & 42 & $0.98(0.88-1)$ & & & & \\
\hline
\end{tabular}

(1): $\mathrm{Sn}$ or $\mathrm{Sp} \geq 80 \%$, and Youden index $\geq 0.20$. (2): cutpoints refer to oxygen saturation decrease of at least 1, 2 or 3 points as compared to the stable phase, heart rate increase of at least $10-15$ beats $/ \mathrm{min}$ as compared to the stable phase and walking distance decrease of at least $35-40 \mathrm{~m}$ as compared to the stable phase. HF: heart failure, COPD: chronic obstructive pulmonary disease, Sn: sensitivity, Sp: specificity, CI: confidence interval; $n$ : sample size.

\subsection{Diagnostic Performance of the Developed Algorithms}

For both conditions, a diagnostic algorithm could be developed by following the parallel testing strategy. We studied up to 23 HF models and 16 COPD models. Table 4 shows HF and COPD models with the highest diagnostic performance and clinical consistency, according to the researchers' opinion. The AUC of the COPD model was 0.921 (95\% CI: 0.847-0.995) and that of the HF model was 0.841 (95\% CI: 0.741-0.941). 
It was not possible to develop a model with the serial testing strategy (only one parameter with Sn $>80 \%$ and Youden index $>0.2$ was found).

Table 4. Diagnostic performance of the developed clinical algorithms.

\begin{tabular}{|c|c|c|c|c|c|c|c|}
\hline Disease & Clinical Parameter & Cutpoint & $n$ & Sn $(95 \%$ CI $)$ & $n$ & Sp (95\% CI) & ROC Area $(95 \% \mathrm{CI})$ \\
\hline $\mathrm{HF}$ & $\begin{array}{c}\text { Oxygen saturation decrease (mean-of-effort } \\
\text { period) of at least } 2 \text { points; } \\
\text { heart rate increase (mean-of-effort period) of at } \\
\text { least } 10 \text { beats } / \text { min; } \\
\text { Walking distance decrease of at least } 40 \mathrm{~m}\end{array}$ & $\begin{array}{l}\text { at least } \\
1 \text { condition }\end{array}$ & 33 & $0.85(0.69-0.93)$ & 28 & $0.75(0.57-0.87)$ & $0.841(0.741-0.941)$ \\
\hline COPD & $\begin{array}{c}\text { oxygen saturation decrease (average of minute } \\
1 \text { to } 3 \text { of effort period) of at least } 2 \text { points } \\
\text { heart rate increase (end-of-effort) of at least } \\
10 \text { beats } / \text { min } \\
\text { Walking distance decrease of at least } 35 \mathrm{~m}\end{array}$ & $\begin{array}{l}\text { at least } \\
1 \text { condition }\end{array}$ & 31 & $0.9(0.75-0.97)$ & 27 & $0.89(0.72-0.96)$ & $0.921(0.847-0.995)$ \\
\hline
\end{tabular}

HF: heart failure, COPD: chronic obstructive pulmonary disease; Sn: sensitivity; Sp: specificity; CI: confidence interval; ROC: Receiver Operating Characteristic; $n$ : sample size.

\section{Discussion}

\subsection{Main Results}

An important observation about the discriminatory power of the here-presented models is that all parameters have to be evaluated in effort $\left(\mathrm{HR}, \mathrm{SaO}_{2}\right.$, and walking distance); this reinforces the proposal that physical exercise may have unmasking effects on potential $\mathrm{HR}$ and/or $\mathrm{SaO}_{2}$ alterations, which would not be observed at rest at the beginning of an exacerbation episode. Not differentiating between rest and effort could partially account for the failure to observe significant variations in these parameters during exacerbation, reported by other authors [12,24,35].

Parameter $\mathrm{SaO}_{2}$ shows the largest differences between the stable and exacerbation phases, especially in COPD. This finding is relevant because $\mathrm{SaO}_{2}$ can be easily measured. Although $\mathrm{SaO}_{2}$ drops during exacerbation episodes are well known, this study defines their discriminative power in quantitative terms of diagnostic performance, and, finding that discriminative power is important, they have been considered for the models. It is related with previous studies on HF and COPD. Masip et al. [9] demonstrated the importance of monitoring $\mathrm{SaO}_{2}$ to detect acute $\mathrm{HF}$ in intensive care units, and $\mathrm{SaO}_{2}$ has been described as the physiological variable with the highest discriminatory power in COPD [12]. Given that several of the physiological factors that determine $\mathrm{SaO}_{2}$ are affected in exacerbations of both conditions, it is not unexpected that monitoring $\mathrm{SaO}_{2}$ is useful in both of them.

Interestingly, the walking distance showed a noticeable discriminatory power. Although it has been shown that walking distance varies depending on whether the patient is in an exacerbation or a stable phase of both HF or COPD [36,37], this variable (6-min walking test [6 MWT]) has only been evaluated as a prognostic factor for mortality or readmission to hospital in both conditions [38-41] but not as a diagnostic parameter to detect an exacerbation episode which is already in course. The findings in this study describe this latter use, defining important realistic cutpoints ( 35 and $40 \mathrm{~m}$ for COPD and $\mathrm{HF}$, respectively) considering the concept of minimal clinically important difference previously described in other studies (15-30 m [42]).

\subsection{Clinical Usefulness/Feasibility}

We conducted the present study bearing in mind the possible implementation of the developed models into a telemedicine system. In this regard, we consider that the Sn and Sp reported for the COPD model are relevant; although the HF ones are not, since the $75 \%$ Sp would result in a number of false-positive detections and consequent alarms, which hinder its clinical applicability. In terms of feasibility, the model could be implemented through a computer application on a mobile device (mobile phone), which would receive and process data from a pulse-oximeter $\left(\mathrm{HR}\right.$ and $\left.\mathrm{SaO}_{2}\right)$. The walking distance could also be measured through the patient's mobile phone. 


\subsection{Validity/Bias}

Since the sample included patients admitted to second- and third-level hospitals, a wide range of the clinical spectrum of these conditions is expected to be represented. However, the models developed in this research were focused on patients with severe exacerbation episodes (those for which hospitalization is required); therefore, these models do not cover the population affected by milder exacerbations (for which ambulatory treatment is usually enough). Participants affected by exacerbations requiring hospitalization were selected because telemedicine systems are usually considered for patients with more severe disease. Additionally, since all participants included in this research already suffered from known HF or COPD, the models cannot be considered for people without HF or COPD background in their medical record (e.g., patients with new-onset HF or COPD who present an exacerbation episode).

We recognize the possibility of influencing the discriminatory power of the models by including participants with exacerbation of both conditions. However, because of the convergence of physiopathological mechanisms, we consider that the influence of this selection bias is limited. For example, in a study by Masip et al. [9] the $\mathrm{SaO}_{2}$ cutpoint for detecting $\mathrm{HF}$ did not change in patients that also suffered from COPD. Moreover, cases of patients simultaneously affected by both conditions are increasingly frequent.

Although guidelines for 6 MWT [43] recommend conducting two tests (learning effect has been demonstrated), only one test was allowed at hospital (exacerbation phase) because it was expected that participants would be too tired to repeat the walking session. Such limitation could adversely influence the discriminatory power of walking distance. However, this influence is expected to be minor since guidelines also recognize that when walking distance is used to assess hospitalization risk or mortality the learning effect may be less important and one test may be sufficient.

Additionally, as the reference for the stable phase, we used the patient's situation after an exacerbation episode, where a potential latent functional deterioration might influence the walking distance, as compared with the distance that would be measured before exacerbation. However, such a bias would make walking distance an even more sensitive discriminatory parameter.

\subsection{Limitations}

Due to the restricted sample size, we used all the data to develop the algorithms; thus, their validation is still pending. Evaluations in the exacerbation phase were conducted after the most severe part of an episode had passed, because that was similar to the beginning of an exacerbation episode, which is the most important moment to take action. We recruited participants in an exacerbation phase and we did not start with a cohort in a stable phase because of the cost and effort associated with the follow-up (not all patients would suffer exacerbation during follow-up or some could take a long time to do so). Considering this design, a specific timeframe for the model (e.g., one week before hospitalization occurred) could not be defined.

\section{Conclusions}

Monitoring physiological variables during effort situations (e.g., walking) may improve the discriminatory power of algorithms based on such physiological parameters for the detection of exacerbation episodes of both HF and COPD.

$\mathrm{SaO}_{2}$ shows the largest differences between the stable and exacerbation phases, especially in COPD. Discriminatory power in quantitative terms of diagnostic performance has been defined.

The diagnostic models presented here should be considered preliminary; they need further study and timeframes for them to be defined. 
Author Contributions: Conceptualization, A.R.-M. and C.G.-B.; formal analysis, C.G.-B., A.R.-M., and F.V.-Á.; funding acquisition, A.R.-M.; investigation, C.G.-B. and A.R.-M.; methodology, C.G.-B. and A.R.-M.; resources, C.G.-B., A.R.-M., F.V.-Á., J.R., F.F., D.C., R.B., and C.I.; supervision, C.G.-B., A.R.-M., F.V.-Á., J.R., F.F., D.C., R.B., and C.I.; writing—original draft preparation, C.G.-B. and A.R.-M.; writing—review and editing, C.G.-B., A.R.-M., F.V.-Á., J.R., F.F., D.C., R.B., and C.I.

Funding: This research was partially funded by the European Commission (enhanced Complete Ambient Assisted Living Experiment (eCaalyx) project); grant number PI08/90944.

Acknowledgments: We thank J. Aguiló, C. Abeledo, M. Peraire, J. Blanch, X. García, A. Cardiel, P. Carbonell, D. Blancas, C. Guevara, M. Riera-Pagespetit, N. Gonzalo, E. Valldosera, and A. Yuste for their support during the study.

Conflicts of Interest: The authors declare no conflict of interest; the funders had no role in study design, data collection, analysis and interpretation, decision to publish the results, or preparation of the manuscript.

\section{References}

1. Boult, C.; Altmann, M.; Gilbertson, D.; Yu, C.; Kane, R.L. Decreasing disability in the 21st century: The future effects of controlling six fatal and nonfatal conditions. Am. J. Public Health 1996, 86, 1388-1393. [CrossRef] [PubMed]

2. Mannino, D.M. COPD: Epidemiology, prevalence, morbidity and mortality, and disease heterogeneity. Chest 2002, 121 (Suppl. 5), 121S-126S. [CrossRef]

3. MuñizGarcía, J.; Crespo Leiro, M.G.; Castro Beiras, A. Epidemiology of heart failure in Spain and the importance of adhering to clinical practice guidelines. Rev. Esp. Cardiol. 2006, 6 (Suppl. F), 2-8.

4. Anzueto, A.; Sethi, S.; Martinez, F.J. Exacerbations of chronic obstructive pulmonary disease. Proc. Am. Thorac. Soc. 2007, 4, 554-564. [CrossRef] [PubMed]

5. Giamouzis, G.; Kalogeropoulos, A.; Georgiopoulou, V.; Laskar, S.; Smith, A.L.; Dunbar, S.; Triposkiadis, F.; Butler, J. Hospitalization epidemic in patients with heart failure: Risk factors, risk prediction, knowledge gaps, and future directions. J. Card. Fail. 2011, 17, 54-75. [CrossRef] [PubMed]

6. Liao, L.; Allen, L.A.; Whellan, D.J. Economic burden of heart failure in the elderly. Pharmacoeconomics 2008, 26, 447-462. [CrossRef] [PubMed]

7. Adamson, P.B.; Smith, A.L.; Abraham, W.T.; Kleckner, K.J.; Stadler, R.W.; Shih, A.; Rhodes, M.M. Continuous autonomic assessment in patients with symptomatic heart failure: Prognostic value of heart rate variability measured by an implanted cardiac resynchronization device. Circulation 2004, 110, 2389-2394. [CrossRef] [PubMed]

8. Javed, F.; Farrugia, S.; Colefax, M.; Schindhelm, K. Early Warning of Acute Decompensation in Heart Failure Patients Using a Noncontact Measure of Stability Index. IEEE Trans. Biomed. Eng. 2016, 63, 438-448. [CrossRef]

9. Masip, J.; Gayà, M.; Páez, J.; Betbesé, A.; Vecilla, F.; Manresa, R.; Ruíz, P. Pulse oximetry in the diagnosis of acute heart failure. Rev. Esp. Cardiol. (Engl. Ed.) 2012, 65, 879-884. [CrossRef]

10. Zhang, J.; Goode, K.M.; Cuddihy, P.E.; Cleland, J.G.F. Predicting hospitalization due to worsening heart failure using daily weight measurement: Analysis of the Trans-European Network-Home-Care Management System (TEN-HMS) study. Eur. J. Heart Fail 2009, 11, 420-427. [CrossRef]

11. Anand, I.S.; Tang, W.H.W.; Greenberg, B.H.; Chakravarthy, N.; Libbus, I.; Katra, R.P.; Music Investigators. Design and performance of a multisensor heart failure monitoring algorithm: Results from the multisensor monitoring in congestive heart failure (MUSIC) study. J. Card. Fail. 2012, 18, 289-295. [CrossRef] [PubMed]

12. Al Rajeh, A.M.; Hurst, J.R. Monitoring of Physiological Parameters to Predict Exacerbations of Chronic Obstructive Pulmonary Disease (COPD): A Systematic Review. J. Clin. Med. 2016, 5, 108. [CrossRef] [PubMed]

13. Hurst, J.R.; Donaldson, G.C.; Quint, J.K.; Goldring, J.J.P.; Patel, A.R.C.; Wedzicha, J.A. Domiciliary pulse-oximetry at exacerbation of chronic obstructive pulmonary disease: Prospective pilot study. BMC Pulm. Med. 2010, 10, 52. [CrossRef] [PubMed]

14. Van den Berge, M.; Hop, W.C.; van der Molen, T.; van Noord, J.A.; Creemers, J.P.; Schreurs, A.J.; Wouters, E.F.; Postma, D.S. Prediction and course of symptoms and lung function around an exacerbation in Chronic Obstructive Pulmonary Disease. Respir. Res. 2012, 13, 44. [CrossRef] [PubMed] 
15. Jensen, M.H.; Cichosz, S.L.; Dinesen, B.; Hejlesen, O.K. Moving prediction of exacerbation in chronic obstructive pulmonary disease for patients in telecare. J. Telemed. Telecare 2012, 18, 99-103. [CrossRef] [PubMed]

16. Yañez, A.M.; Guerrero, D.; Pérez de Alejo, R.; Garcia-Rio, F.; Alvarez-Sala, J.L.; Calle-Rubio, M.; de Molina, R.M.; Falcones, M.V.; Ussetti, P.; Sauleda, J.; et al. Monitoring breathing rate at home allows early identification of COPD exacerbations. Chest 2012, 142, 1524-1529. [CrossRef]

17. Martín-Lesende, I.; Orruño, E.; Bilbao, A.; Vergara, I.; Cairo, M.C.; Bayón, J.C.; Reviriego, E.; Romo, M.I.; Larrañaga, J.; Asua, J.; et al. Impact of telemonitoring home care patients with heart failure or chronic lung disease from primary care on healthcare resource use (the TELBIL study randomised controlled trial). BMC Health Serv. Res. 2013, 13, 118. [CrossRef]

18. Sund, Z.M.; Powell, T.; Greenwood, R.; Jarad, N.A. Remote daily real-time monitoring in patients with COPD—A feasibility study using a novel device. Respir. Med. 2009, 103, 1320-1328. [CrossRef]

19. Hardinge, M.; Rutter, H.; Velardo, C.; Shah, S.A.; Williams, V.; Tarassenko, L.; Farmer, A. Using a mobile health application to support self-management in chronic obstructive pulmonary disease: A six-month cohort study. BMC Med. Inform. Decis. Mak. 2015, 15, 46. [CrossRef]

20. Riis, H.C.; Jensen, M.H.; Cichosz, S.L.; Hejlesen, O.K. Prediction of exacerbation onset in chronic obstructive pulmonary disease patients. J. Med. Eng. Technol. 2016, 40, 1-7. [CrossRef]

21. Mohktar, M.S.; Redmond, S.J.; Antoniades, N.C.; Rochford, P.D.; Pretto, J.J.; Basilakis, J.; Lovell, N.H.; McDonald, C.F. Predicting the risk of exacerbation in patients with chronic obstructive pulmonary disease using home telehealth measurement data. Artif. Intell. Med. 2015, 63, 51-59. [CrossRef] [PubMed]

22. Ledwidge, M.T.; O’Hanlon, R.; Lalor, L.; Travers, B.; Edwards, N.; Kelly, D.; Voon, V.; McDonald, K.M. Can individualized weight monitoring using the HeartPhone algorithm improve sensitivity for clinical deterioration of heart failure? Eur. J. Heart Fail. 2013, 15, 447-455. [CrossRef] [PubMed]

23. Shah, S.A.; Velardo, C.; Farmer, A.; Tarassenko, L. Exacerbations in Chronic Obstructive Pulmonary Disease: Identification and Prediction Using a Digital Health System. J. Med. Internet Res. 2017, 19, e69. [CrossRef] [PubMed]

24. Gilliam, F.R., III; Ewald, G.A.; Sweeney, R.J. Feasibility of Automated Heart Failure Decompensation Detection Using Remote Patient Monitoring: Results from the Decompensation Detection Study. J. Innov. Cardiac. Rhythm. Manag. 2012, 3, 735-745.

25. Cohen-Solal, A.; Logeart, D.; Guiti, C.; Dahan, M.; Gourgon, R. Cardiac and peripheral responses to exercise in patients with chronic heart failure. Eur. Heart J. 1999, 20, 931-945. [CrossRef] [PubMed]

26. Bartels, M.N.; Jelic, S.; Ngai, P.; Basner, R.C.; DeMeersman, R.E. High-frequency modulation of heart rate variability during exercise in patients with COPD. Chest 2003, 124, 863-869. [CrossRef] [PubMed]

27. Van Gestel, A.J.R.; Kohler, M.; Steier, J.; Sommerwerck, U.; Teschler, S.; Russi, E.W.; Teschler, H. Cardiac autonomic function and cardiovascular response to exercise in patients with chronic obstructive pulmonary disease. COPD J. Chronic Obstr. Pulm. Dis. 2012, 9, 160-165. [CrossRef] [PubMed]

28. Dolgin, M.; New York Heart Association. Nomenclature and Criteria for Diagnosis of Diseases of the Heart and Great Vessels/The Criteria Committee of the New York Heart Association, 9th ed.; Little, Brown: Boston, MA, USA, 1994; ISBN 0316605387.

29. Fletcher, C. Standardised questionnaire on respiratory symptoms: A statement prepared and approved by the MRC Committee on the Aetiology of Chronic Bronchitis (MRC breathlessness score). BMJ 1960, 2, 1665.

30. Borg, G.A. Psychophysical bases of perceived exertion. Med. Sci. Sports Exerc. 1982, 14, 377-381. [CrossRef]

31. Gordis, L. Epidemiology, 5th ed.; Elsevier Saunders: Philadelphia, PA, USA, 2014; pp. 88-115.

32. Youden, W.J. Index for rating diagnostic tests. Cancer 1950, 3, 32-35. [CrossRef]

33. Bieri, D.; Reeve, R.A.; Champion, G.D.; Addicoat, L.; Ziegler, J.B. The Faces Pain Scale for the self-assessment of the severity of pain experienced by children: Development, initial validation, and preliminary investigation for ratio scale properties. Pain 1990, 41, 139-150. [CrossRef]

34. Herr, K.A.; Mobily, P.R.; Kohout, F.J.; Wagenaar, D. Evaluation of the Faces Pain Scale for use with the elderly. Clin. J. Pain 1998, 14, 29-38. [CrossRef] [PubMed]

35. Burton, C.; Pinnock, H.; McKinstry, B. Changes in telemonitored physiological variables and symptoms prior to exacerbations of chronic obstructive pulmonary disease. J. Telemed. Telecare 2015, 21, 29-36. [CrossRef] [PubMed] 
36. Alahmari, A.D.; Patel, A.R.C.; Kowlessar, B.S.; Mackay, A.J.; Singh, R.; Wedzicha, J.A.; Donaldson, G.C. Daily activity during stability and exacerbation of chronic obstructive pulmonary disease. BMC Pulm. Med. 2014, 14, 98. [CrossRef] [PubMed]

37. Collins, S.P.; Thorn, M.; Nowak, R.M.; Levy, P.D.; Fermann, G.J.; Hiestand, B.C.; Cowart, T.D.; Venuti, R.P.; Hiatt, W.R.; Foo, S.; et al. Feasibility of Serial 6-min Walk Tests in Patients with Acute Heart Failure. J. Clin. Med. 2017, 6, 84. [CrossRef] [PubMed]

38. McCabe, N.; Butler, J.; Dunbar, S.B.; Higgins, M.; Reilly, C. Six-minute walk distance predicts 30-day readmission after acute heart failure hospitalization. Heart Lung 2017, 46, 287-292. [CrossRef] [PubMed]

39. Tabata, M.; Shimizu, R.; Kamekawa, D.; Kato, M.; Kamiya, K.; Akiyama, A.; Kamada, Y.; Tanaka, S.; Noda, C.; Masuda, T. Six-minute walk distance is an independent predictor of hospital readmission in patients with chronic heart failure. Int. Heart J. 2014, 55, 331-336. [CrossRef]

40. Ingle, L.; Cleland, J.G.; Clark, A.L. The long-term prognostic significance of 6-minute walk test distance in patients with chronic heart failure. BioMed Res. Int. 2014, 2014, 505969. [CrossRef]

41. Dajczman, E.; Wardini, R.; Kasymjanova, G.; Préfontaine, D.; Baltzan, M.A.; Wolkove, N. Six minute walk distance is a predictor of survival in patients with chronic obstructive pulmonary disease undergoing pulmonary rehabilitation. Can. Respir. J. 2015, 22, 225-229. [CrossRef]

42. Bohannon, R.W.; Crouch, R. Minimal clinically important difference for change in 6-minute walk test distance of adults with pathology: A systematic review. J. Eval. Clin. Pract. 2017, 23, 377-381. [CrossRef]

43. Holland, A.E.; Spruit, M.A.; Troosters, T.; Puhan, M.A.; Pepin, V.; Saey, D.; McCormack, M.C.; Carlin, B.W.; Sciurba, F.C.; Pitta, F.; et al. An official European Respiratory Society/American Thoracic Society technical standard: Field walking tests in chronic respiratory disease. Eur. Respir. J. 2014, 44, 1428-1446. [CrossRef] [PubMed]

(C) 2019 by the authors. Licensee MDPI, Basel, Switzerland. This article is an open access article distributed under the terms and conditions of the Creative Commons Attribution (CC BY) license (http://creativecommons.org/licenses/by/4.0/). 